\title{
Governança na internet: um estudo sobre o Marco Civil brasileiro
}

\section{Laura Vilela Rodrigues Rezende 1 Meyrielle Rodrigues de Lima²}

Recibido: 2015-03-04

Enviado a pares: 2015-03-05
Aprobado por pares: 2015-05-15

Aceptado: 2015-05-25

DOI: 10.5294/pacla.2016.19.1.6

\section{Para citar este artículo / To reference this article / Para citar este artigo}

Rodrigues Rezende, L. V. y Rodrigues de Lima, M. (Marzo de 2016). Governança na internet: um estudo sobre o Marco Civil brasileiro. Palabra Clave, 19(1), 133-155. DOI: 10.5294/pacla.2016.19.1.6

\section{Resumo}

Este trabalho tem como objetivo realizar um estudo sobre a legislação que rege o uso da internet no Brasil, o Marco Civil da Internet (Lei $12.965 / 2014)$. Trata-se de uma pesquisa descritiva, de natureza qualitativa, com base em levantamento bibliográfico e estudo comparativo. Expõese inicialmente um breve histórico da internet no Brasil e o seu panorama atual. Em seguida, é apresentado o conceito de governança na internet e os acontecimentos que marcaram as discussões acerca dessa temática. Abordase o Marco Civil da Internet no Brasil, o histórico de sua criação e os princípios que o regem. Conclui-se que ele é um importante instrumento oficial regulatório para assegurar a liberdade e os direitos do usuário. Sua concepção foi fundamentada na participação da sociedade civil, o que pode ser considerado inédito no tocante à criação de leis regulatórias. Considera-se que esta seja uma lei sofisticada quanto às suas diretrizes, o que a torna uma 
das mais progressistas do mundo. Apesar disso, sua trajetória democrática de criação confere a ela um caráter generalista e superficial.

\section{Palavras-chave}

Internet, informação e desenvolvimento, comunicação e desenvolvimento, Brasil (Fonte: Tesauro da Unesco).

\section{Gobernanza en Internet: un estudio acerca del Marco Civil brasileño}

\section{Resumen}

El trabajo tiene como propósito realizar un estudio sobre la legislación que rige el uso de Internet en Brasil, en el Marco Civil de Internet (Ley 12.965/2014). Se trata de una investigación descriptiva, de naturaleza cualitativa, basada en recopilación bibliográfica y estudio comparativo. Se expone inicialmente un breve histórico de Internet en Brasil y su panorama actual. Luego, se presenta el concepto de gobernanza en Internet y los sucesos que marcaron las discusiones acerca de esta temática. Se aborda el Marco Civil de Internet en Brasil, el histórico de su creación y los principios que lo rigen. Se concluye que es un importante instrumento oficial reglamentario para asegurar la libertad y los derechos del usuario. Su concepción se fundamentó en la participación de la sociedad civil, lo que puede considerarse inédito en lo que se refiere a la creación de leyes reglamentarias. Se considera que esta sea una ley sofisticada en cuanto a sus directrices, lo que la vuelve una de las más progresistas del mundo. Pese a todo lo anterior, su trayectoria democrática de creación le otorga un carácter generalista y superficial.

\section{Palabras clave}

Internet, información y desarrollo, comunicación y desarrollo, Brasil (Fuente: Tesauro de la Unesco). 


\section{Governance of the Internet: A Study of the Brazilian Civil Framework}

\section{Abstract}

The paper aims to conduct a study on the legislation governing the use of the Internet in Brazil, the Civil Internet Framework (Law 12,965 / 2014). This is a descriptive study, of qualitative nature, based on bibliography and comparative study. A brief history of the Internet in Brazil and its current outlook is initially exposed. Then, the concept of governance in the Internet and the events that marked the discussions on this subject is presented. The Civil Internet Framework addresses in Brazil, the history of its creation and the principles that govern it. We conclude that it is an important official regulatory instrument to ensure freedom and rights of the user. Its design was based on the participation of civil society, which can be considered unprecedented in regard to creating regulatory laws. It is considered that this is a sophisticated law as to its guidelines, which makes it one of the most progressive in the world. Despite all this, its democratic trajectory of creation gives a general and superficial character.

\section{Keywords}

Internet, information and development, communication and development, Brazil (Source: Unesco Thesaurus). 


\section{Introdução}

As discussões internacionais acerca das definições ligadas à temática da governança da internet vêm acontecendo há mais de uma década. Os países possuem preocupações quanto às políticas públicas relevantes a essa temática, entendimento comum dos papéis e responsabilidades de todos os atores envolvidos nesse cenário: desde os governos e organizações internacionais até a sociedade civil como um todo.

Araya e Vidotti (2010) afirmam que a informação no meio digital possui suas próprias implicações e que o produtor/usuário de informação deve estar ciente dos aspectos legais que ela acarreta.

As leis que regem a internet não existem somente no Brasil. Com a criação do Grupo de Trabalho sobre Governança da Internet (Working Group on Internet Governance -WGIG_-) em 2003, formado por 40 membros de governos, sociedades civis e setores privados de várias partes do mundo, começaram as discussões sobre um modelo de governança da internet. Definiu-se que governança da internet é o desenvolvimento e a execução de normas, regras, princípios e tomadas de decisão, adotados por governos, setores privados e sociedades civis, no que se refere à evolução e ao uso da internet (Working Group on Internet Governance, 2005).

A internet se popularizou no Brasil no final da década de 1990, porém, somente em 2014, surgiu uma lei que regulamentasse os direitos e deveres dos usuários. Antes da criação desse marco regulatório, os projetos de lei cujos assuntos estavam relacionados com a internet tinham um caráter criminal, o que levou a discussões e protestos que culminaram no embrião do Marco Civil da Internet.

Em estudo realizado pela Comscore (2013), uma empresa que faz pesquisa de mercado com foco em análise da internet, constatou-se que o Brasil é o sétimo país, no âmbito mundial, e o maior da América Latina em acessos à rede. Foi verificado também que o brasileiro passa em média 27 horas mensais on-line. 
A Lei 12.965, de 23 de abril de 2014, conhecida como Marco Civil da Internet, pauta seus princípios na neutralidade da rede, liberdade de expressão e privacidade do usuário. A criação da lei, em duas etapas, contou com efetiva participação da população por meio de canais para discussão dos aspectos que seriam abordados por ela.

Embora a Lei do Marco Civil seja nova, moderna e tenha sido construída de forma democrática, com a ajuda dos cidadãos, entende-se que se faz necessário um relato sobre a trajetória de sua criação e uma análise do impacto desta quanto à atuação do usuário na internet. Portanto, o presente estudo objetiva apresentar um relato histórico da criação do Marco Civil da Internet brasileiro, caracterizá-lo para, em seguida, realizar uma análise de seus impactos no tocante à atuação do usuário na rede mundial de computadores.

\section{Métodos}

De acordo com os aspectos metodológicos, este trabalho consiste numa pesquisa descritiva, de natureza qualitativa, com base em levantamento bibliográfico de leis e outros regulamentos. Pretende-se comparar algumas das principais ações do usuário, citadas no texto da lei, anteriores à sanção da lei e como serão a partir de sua vigência.

\section{Histórico da internet no Brasil}

As primeiras discussões sobre a criação de uma rede de transmissão de dados no Brasil se deram após o início da década de 1970, quando houve um aumento no número de compras de equipamentos de informática no país. Até então, os principais computadores existentes em território nacional encontravam-se em posse de universidades e agências governamentais (Universidade Estadual de Maringá, 2006). No cenário internacional, já ocorria a implantação de redes para transmissão de dados uma vez que as redes de telefonia existentes não ofereciam qualidade suficiente para esse fim (Benakouche, 1997).

Em 1979, foi criada a Secretaria Especial de Informática (SEI), que posteriormente criou a Comissão Especial de Teleinformática, responsável 
por direcionar os rumos para o desenvolvimento do setor, de maneira que houvesse melhor integração com a Política Nacional de Informática. A SEI foi também responsável pelas decisões exclusivas sobre a transferência de dados para o exterior e era quem decidia autorizar seu uso ou não (Carvalho, 2006). A SEI se tornou subordinada ao Serviço Nacional de Inteligência, o que acarretou na interferência militar nos assuntos de informática do país. Essa interferência intimidou professores universitários e membros de empresas estatais, que foram chamados para depor pelos militares para a construção de um relatório sobre a situação informática (Marques, 2000). Essa intervenção marcou um retrocesso no avanço tecnológico que vinha até então sendo desenvolvido e fez com que o setor entrasse em crise.

Na década de 1980, os microcomputadores se tornaram mais populares, o que provocou o surgimento de comunidades virtuais, denominadas Computer Bulletin Board Systems (BBS), um espaço virtual onde seus usuários pudessem trocar informações.

Em 1984, foi lançada a "Lei da Informática”, primeira lei a respeito de informática no Brasil, que propunha a criação de uma reserva de mercado para incentivar a criação de produtos nacionais de informática.

Em 1989, o Ministério da Ciência e Tecnologia criou a Rede Nacional de Ensino e Pesquisa (RNP), com a intenção de construir a infraestrutura para a criação de uma rede nacional de internet para a comunidade acadêmica.

No final de 1994, a Embratel $^{3}$ anunciou o lançamento, em caráter experimental, do acesso comercial à internet. Num primeiro momento, o acesso foi limitado a empresas que fossem "fornecedoras de informação", como agências de notícias, livrarias e editoras (Embratel, 1994).

Em 1995, por meio da Portaria Interministerial 147, de 31 de maio, foi criado, pelo Ministério das Comunicações e Ministério da Ciência e Tec-

3 Embratel: Empresa Brasileira de Telecomunicações. No período citado, a Embratel era uma empresa de economia mista de controle estatal responsável pelos serviços de telecomunicações do país. Em 1998, a Embratel foi privatizada. 
nologia, o Comitê Gestor da Internet no Brasil (CGI.br), com o objetivo de "assegurar qualidade e eficiência dos serviços ofertados, justa e livre competição entre provedores, e manutenção de padrões de conduta de usuários e provedores, e considerando a necessidade de coordenar e integrar todas as iniciativas de serviços Internet no país” (Brasil, 1995a, não paginado).

A Portaria 148, de 31 de maio de 1995, veio com o objetivo de regular a Rede Pública de Telecomunicações para serviços de conexão à internet (Brasil, 1995b). Os provedores privados de internet seriam os responsáveis por enviar internet aos usuários finais, mediante pagamento de uma taxa às empresas públicas de telecomunicações, que ficariam responsáveis apenas pela infraestrutura.

De acordo com Carvalho, Arita e Nunes (1999), em 1996, ocorreu a primeira grande explosão da internet no país. Com as redes de telecomunicações que cuidavam apenas da infraestrutura, houve o aumento de um milhão de usuários finais e cem mil hosts ${ }^{4}$.

Em 1999, foi criado o Programa Sociedade da Informação (SocInfo), coordenado pelo Ministério da Ciência e Tecnologia, com o objetivo de "integrar, coordenar e fomentar ações para a utilização de tecnologias de informação e comunicação, de forma a contribuir para a inclusão social de todos os brasileiros na nova sociedade e, ao mesmo tempo, contribuir para que a economia do País tenha condições de competir no mercado global” (Menezes, Santos, 2002, não paginado).

O programa foi dividido em três etapas: estudos preliminares; detalhamento de ações que foram publicadas no Livro Verde ${ }^{5}$ em 2000; resultado de consulta feita à sociedade, publicada no Livro Branco ${ }^{6}$, em 2002 (Araújo, Rocha, 2009).

4 Host é o nome dado para o computador ou máquina responsável por oferecer recursos, informações ou serviços a usuários e clientes (Viana, 2012).

5 Disponível em: http://www.mct.gov.br/upd_blob/0004/4795.pdf

6 Disponível em: http://www.cgee.org.br/arquivos/livro_branco_cti.pdf 
No final de 1999, foram anunciadas novidades sobre banda larga no Brasil. Segundo Lutfi (1999), a internet, a partir do ano 2000, poderia ser acessada pelo usuário por meio de cabos de televisão por assinatura, linhas telefônicas ADSL e ISDN, e micro-ondas (wireless).

Em 2005, o Instituto Brasileiro de Geografia e Estatística (IBGE) investigou o acesso à internet por meio da Pesquisa Nacional por Amostra de Domicílios. O resultado mostrou que "do total da população de 10 anos ou mais de idade, $21 \%$ das pessoas acessavam a internet [...], por meio de um microcomputador, pelo menos uma vez, no período de referência dos últimos três meses" (Instituto Brasileiro de Geografia e Estatística, 2005, não paginado). Em pesquisa semelhante realizada em 2011, o número de pessoas que acessavam a internet, de acordo com os mesmos requisitos anteriores, subiu para aproximadamente 47\% (Instituto Brasileiro de Geografia e Estatística, 2011).

Em 2014, o Centro de Estudos sobre as Tecnologias da Informação e da Comunicação (CETIC.br) publicou dados, referentes ao ano de 2013, a respeito do uso das Tecnologias da Informação e Comunicação (TICs) em domicílios e empresas, escolas brasileiras, centros públicos de acesso, estabelecimentos de saúde e sobre o uso da internet por crianças e adolescentes.

A pesquisa TIC: domicilios 2013 teve como objetivo medir a disponibilidade e uso das tecnologias, entre usuários acima de 10 anos, e foi dividida nos seguintes módulos: acesso às TICs; uso de computadores, local e frequência de uso; uso da internet; governo eletrônico; comércio eletrônico; habilidades com o computador; uso de telefonia móvel; intenção de aquisição de novos aparelhos e serviços de TIC. Foram obtidos como resultado:

- $\quad 49 \%$ dos domicílios possuíam computador, sendo o tipo mais comum o computador de mesa (63\%), e que era o único tipo de computador disponível em 39\% dos municípios;

- $\quad 43 \%$ dos domicílios possuíam acesso à internet, sendo que destes o tipo de acesso mais comum era o via banda larga fixa (66\%), e o meio mais utilizado era a conexão via cabo (34\%); 
- $\quad 58 \%$ dos entrevistados afirmaram que já acessaram a internet alguma vez. $71 \%$ dos usuários afirmaram acessá-la diariamente;

- a maioria dos usuários acessava a internet de casa (78\%);

- as principais atividades realizadas na rede, segundo os entrevistados: comunicação — uso de redes sociais (77\%); busca de informações e transações — procura por informações de produtos e serviços (65\%); multimídia — ouvir música on-line (63\%); educação — realizar atividades ou pesquisas escolares (55\%); downloads, criação e compartilhamento de conteúdo - compartilhar conteúdo na internet (60\%);

- $\quad 68 \%$ afirmaram ter utilizado serviços de governo eletrônico no ano anterior. Os serviços mais utilizados de governo eletrônico foram: obtenção de documentos - consulta de Cadastro de Pessoa Física (27\%); pagamento de taxas e impostos — obtenção de informações sobre impostos e taxas em sites do governo (23\%); previdência e assistência social — obtenção de informações sobre previdência e benefícios sociais (17\%); justiça e segurança — buscar informações sobre direitos do consumidor (19\%); outros serviços — buscar informações sobre serviços públicos de educação (25\%); (58\%) (Centro de Estudos sobre as Tecnologias de Informação e Comunicação, 2014).

Embora a internet tenha sido instalada no Brasil há 20 anos e conte hoje com mais de 100 milhões de usuários, faltava ainda ao país uma lei que regulamentasse os direitos e deveres do usuário, e guiasse as questões relativas à governança da internet.

\section{A governança da internet e o Marco Civil}

Em dezembro de 2003, ocorreu em Genebra a Cúpula Mundial das Nações Unidas sobre a Sociedade da Informação (World Summit on the Information Society - WSIS - ). A partir desse encontro, foi criado o WGIG, formado por 40 membros representantes de governos, setor privado e sociedade civil. Foram realizados ao todo quatro encontros em 2004 e 2005, e os resultados foram divulgados num relatório. 
Durante uma das reuniões, Chefes de Estado e Governo reconheceram a importância da internet como "elemento central da infraestrutura de uma sociedade de informação emergente" (Working Group on Internet Governance, 2005, p. 3, tradução nossa).

O relatório do WGIG apresentou a definição de governança da internet: "governança da internet é o desenvolvimento e execução, aplicados pelos Governos, setores privados e sociedades civis, de princípios compartilhados, normas, regras, procedimentos de tomada de decisão, e programas que figuram a evolução e uso da internet [...]" (Working Group on Internet Governance, 2005, p. 4, tradução nossa).

No Brasil, o CGI.br, em reunião ordinária, ocorrida em 2009, aprovou a resolução Princípios para a governança e uso da internet no Brasil (CGI.BR) $R E S / 2009 / 003 / P)$. No que diz respeito à governança, especificamente, o documento afirma que "a governança da internet deve ser exercida de forma transparente, multilateral e democrática, com a participação dos vários setores da sociedade, preservando e estimulando o seu caráter de criação coletiva. [...] A governança da internet deve promover a contínua evolução e ampla difusão de novas tecnologias e modelos de uso e acesso" (Comitê Gestor da Internet no Brasil, 2009, p. 2).

O Marco Civil da Internet foi pensado como um conjunto de normas que regulamentariam o uso da internet e que teriam como princípios a neutralidade da rede, a privacidade do usuário e a liberdade de expressão.

Planejado em 2009, a proposta era a criação democrática de uma lei com ampla participação da comunidade, a qual contribuiria com sugestões e debates. A fase de criação da lei foi dividida em duas etapas bem-sucedidas. Porém, a aprovação da lei ocorreu somente cinco anos depois, em 2014.

Antes de sua criação, os projetos de lei que tramitavam no Congresso criminalizavam ações ocorridas no ambiente virtual. Dentre eles, vale destacar o Projeto de Lei de Crimes Digitais (Projeto de Lei 84/1999), conhecido como "Lei Azeredo", amplamente rejeitado. Essa proposta de lei 
designava, dentre outras questões, que os provedores de acesso deveriam monitorar as ações dos usuários, a fim de detectar atividades suspeitas sem necessidade de autorização judicial (Souza, Solagna, 2012).

\section{Primeira etapa de criação da Lei do Marco Civil da Internet no Brasil}

Em outubro de 2009, foi lançado o processo colaborativo de construção do Marco Civil da Internet por meio da plataforma pública de blogs e conversas Cultura Digital, além de um fórum para discussões mais amplas (Fundação Getúlio Vargas, 2009).

O blog "Marco Civil da Internet", de endereço <http:// culturadigital.br/marcocivil/>, foi criado dentro do portal Cultura Digital, mantido pelo Ministério da Cultura. O texto para debate foi dividido em três eixos e, para cada aspecto a ser debatido, foi criada uma postagem dentro do blog, com espaço para comentários.

- O primeiro eixo procurava identificar assuntos individuais e coletivos relacionados ao uso da internet.

- $\quad$ O segundo eixo se referia aos responsáveis por viabilizar processos de comunicação por meio da internet, como provedores de acesso, de conteúdo, de serviços, de aplicativos, de hospedagem, usuários criadores de conteúdos criativos e participantes de processos de comunicação em rede.

- $\quad$ O terceiro eixo se propunha a discutir diretrizes para servirem de referência para a formulação de políticas públicas relacionadas com a internet e para a atualização das diretrizes na Lei Geral das Telecomunicações e na Política Nacional de Informática (Lei da Informática), de 1984.

Optou-se por deixar de fora do processo de elaboração alguns temas que, apesar de dialogarem com o Marco Civil, atingem uma esfera que vai além da internet ou que possuem em andamento suas próprias discussões e anteprojetos de lei. São estes: certificação digital, comércio eletrônico, comunicação eletrônica de massa, crimes praticados por meio da internet, 
definição técnica sobre os tipos de serviço de telecomunicações, direito autoral, gestão de nomes e números de Protocolo Internet (IP), governança e gestão político-administrativa da internet, regulação das LAN houses.

Em 17 de dezembro de 2009, chega ao fim a primeira etapa do projeto, que reuniu, segundo informações do blog do Marco Civil, 800 contribuições e em média 1.500 visitas diárias.

\section{Segunda etapa de criação da Lei do Marco Civil da Internet no Brasil}

A segunda etapa do projeto se iniciou em 8 de abril de 2010, com previsão de término para 23 de maio do mesmo ano. Com base nos comentários da população e de entidades durante a primeira fase, foi elaborada a minuta do anteprojeto de lei ${ }^{7}$, que foi divulgada no blog para mais discussões.

Durante o período de discussões, alguns pontos da minuta geraram polêmica, como os artigos relacionados com a retirada de conteúdo e identificação dos usuários (Bonatelli, 2010). Essas discussões acabaram por gerar mudanças no texto da minuta; uma delas se refere à responsabilidade dos provedores quanto ao conteúdo publicado por terceiros (Lemos, 2010).

Vários órgãos internacionais relacionados com a indústria fonográfica, de telecomunicações, universidades, entidades governamentais, demonstraram preocupações e apresentaram contribuições a respeito dos direitos autorais. Embora tenha ficado claro na primeira fase do projeto que esse assunto não seria abordado, foi demonstrada uma enorme preocupação com esse fato, além de questões relacionadas com a neutralidade dos provedores, os quais deveriam ser responsabilizados caso obtivessem vantagens econômicas em cima de materiais protegidos por copyright ou incentivassem a pirataria.

Findo o prazo da segunda etapa, foi divulgado um extenso relatório que continha, além do texto da minuta, os posts com as contribuições pu-

7 Disponível em: http://culturadigital.br/marcocivil/debate/ 
blicados no blog. Segundo Santarém (2010), nesse ínterim, 1.168 novos comentários foram feitos.

\section{Terceira etapa de criação da Lei do Marco Civil da Internet no Brasil}

Antes do projeto de lei ser enviado ao Congresso para votação, outros eventos presenciais ocorreram para discussões acerca do tema. Após todas as discussões, em 24 de agosto de 2011, o Projeto de Lei 2.126/2011 que "estabelece princípios, garantias, direitos e deveres para o uso da Internet no Brasil”, foi apresentado à Câmara dos Deputados (Brasil, 2011a).

Foram realizadas sete audiências públicas e seminários, contando com 67 palestrantes de dezenas de instituições, cujos debates visavam aprofundar os temas abordados nos textos dos projetos, dentre os quais: direitos dos usuários, responsabilidade civil de terceiros, atuação do Poder Público, guarda de logs e privacidade do usuário, liberdade de expressão e o potencial de inovação da internet, neutralidade da rede e governança na internet (Brasil, 2011b).

A matéria do projeto de lei tramitou em regime de Urgência Constitucional e teve prazo de 45 dias para apreciação na Câmara dos Deputados ${ }^{8}$.

Em novembro de 2013, foi deferido um requerimento para a retirada de tramitação do Projeto de Lei 6.112/2013, que "dispõe sobre a responsabilidade penal dos provedores de acesso à rede mundial de computadores — internet e dos provedores de conteúdo ou informações".

Na Sessão do dia 12 de fevereiro de 2014, concluem-se a constitucionalidade, a juridicidade e a boa técnica legislativa do Projeto de Lei 2.126/2011. Porém, a votação passou por um mês de adiamentos e indefinições quanto à matéria.

8 Disponível em: http://www.camara.gov.br/proposicoesWeb/prop_mostrarintegra?codteor=1132586\&filename= Tramitacao-PL+2126/2011 
Por fim, votou-se a redação final, que foi aprovada e assinada pelo relator da Comissão, e enviada ao Senado. Em 22 de abril de 2014, o projeto foi aprovado no Senado e transformou-se na Lei Ordinária 12.965, de 23 de abril de 2014.

A lei foi sancionada pela Presidente da República em 24 de abril de 2014, na abertura do evento NETMundial, que reuniu representantes de mais de 80 países (Aragão, 2014). O objetivo desse evento era discutir dois assuntos considerados importantes para o desenvolvimento e o futuro da internet: princípios da governança da internet e roteiro para a evolução futura desse ecossistema.

Dentre os princípios da governança da internet abordados estão: direitos humanos e valores compartilhados; proteção de intermediários; cultura e diversidade linguística; espaço desfragmentado e unificado; segurança, estabilidade e resiliência da internet; arquitetura aberta e distribuída; ambiente que permite inovação sustentável e criatividade; padrões abertos. O roteiro para evolução futura da governança da internet engloba: questões que merecem atenção de todas as partes interessadas na evolução futura da governança da internet; questões que lidam com melhorias institucionais; questões que lidam com assuntos específicos da governança da internet, tais como segurança e estabilidade, e vigilância arbitrária. $\mathrm{O}$ documento aponta, ainda, questões que precisam ser mais bem discutidas e prospecções futuras (NETMundial, 2014).

Após a sua realização, o CGI.br, no dia 30 de maio de 2014, lançou a resolução Grupo de Trabalho sobre Governança da Internet (Resolução CGI.br/RES/2014/009) a fim de discutir e definir o posicionamento da instituição, no quesito da governança (Comitê Gestor da Internet no Brasil, 2014).

\section{Marco Civil: princípios, garantias, direitos e deveres}

A Lei Ordinária 12.965/2014, que estabelece "princípios, garantias, direitos e deveres para o uso da internet no Brasil”, foi dividida em cinco capítulos e 32 artigos. A seguir, um resumo dos capítulos, exceto o quinto, por se tratar apenas das disposições finais. 
O primeiro capítulo pontua os fundamentos, princípios e objetivos que regem a lei, sendo alguns deles:

- $\quad$ o respeito à liberdade de expressão;

- os direitos humanos e o exercício da cidadania em meio digital;

- manifestação livre do pensamento com base na Constituição Federal;

- $\quad$ proteção da privacidade do usuário e de seus dados pessoais;

- $\quad$ preservação e garantia da neutralidade da rede;

- $\quad$ preservação da natureza participativa da rede;

- direito de acesso à internet, à informação e ao conhecimento.

O segundo capítulo trata dos direitos e garantias do usuário. Parte-se do princípio de que o acesso à internet é essencial para o exercício da cidadania; portanto, o usuário tem o direito a:

- ter sua vida privada e intimidade preservadas, e, em caso de violação, o direito à indenização;

- $\quad$ inviolabilidade e sigilo do fluxo de comunicações pela internet e comunicações privadas armazenadas, exceto por ordem judicial.

A respeito dos dados pessoais, registros de conexão e aplicações de internet, é vedado aos provedores de aplicações que armazenem esses dados dos usuários, exceto pela sua autorização, que poderá ser cancelada a qualquer momento e, consequentemente, os dados totalmente excluídos. Segundo Oliveira (2014), com isso se evitará que o usuário seja alvo de propagandas e serviços indesejados.

O terceiro capítulo aborda a provisão de conexões e serviços de aplicações. De acordo com esse capítulo, a rede deve ser neutra, ou seja, os pacotes de dados não devem conter distinção entre conteúdo, origem e destino, serviço, terminal ou aplicação. Serão admitidas exceções em casos especiais, como em serviços de emergência. Bernes-Lee (2014), criador do World Wide Web, em discurso no NETMundial, reafirmou a importância da neutralidade da rede para mantê-la um ambiente livre de discriminação comercial e política. 
Esse capítulo também traz questões referentes aos provedores de conexão à internet no tocante à coleta, guarda, armazenamento e tratamento de registros de dados, respeitando-se o sigilo destes. Fica disposto também que os provedores de conexão não serão responsabilizados por conteúdo danoso gerado por terceiros. Também não será responsabilizado o provedor de aplicações exceto se, por determinação judicial, o conteúdo não for retirado do ar.

O quarto capítulo da lei aborda a atuação do Poder Público. Ele define diretrizes para a atuação da União, dos Estados, dos Municípios e do Distrito Federal para o desenvolvimento da internet e as aplicações de internet utilizadas pelo Poder Público. Esse capítulo também trata do papel do Estado na educação e o uso da internet como ferramenta para o exercício da cidadania, promoção cultural e desenvolvimento tecnológico. Finalizando, expõe os deveres das iniciativas públicas de fomento à cultura digital e promoção da internet como ferramenta social.

\section{Impactos do Marco Civil na atuação do cidadão}

Para analisar as mudanças na atuação dos usuários brasileiros na internet com a sanção do Marco Civil, optou-se pela caracterização das seguintes ações realizadas por estes na internet, com base no próprio texto da lei:

- $\quad$ redes sociais digitais;

- $\quad$ criação de conteúdo (sites, blogs, wikis);

- $\quad$ acesso à informação (exercícios de cidadania na internet (cibercidadania), tais como: fiscalização de gastos públicos, assinatura de petições etc.;

- comunicação em tempo real (correio eletrônico, grupos e fóruns de discussão).

Os resultados serão apresentados a seguir num quadro comparativo entre essas ações antes e depois de a lei do Marco Civil na Internet entrar em vigor. 


\section{Quadro 1 \\ Impacto do Marco Civil nas atividades realizadas pelos usuários}

\begin{tabular}{|l|c|c|}
\hline \multicolumn{1}{|c|}{ Caracterização das ações } & Antes do Marco Civil & O que muda com o Marco Civil \\
\hline Redes Sociais digitais & $\begin{array}{c}\text { Os dados dos usuários poderiam } \\
\text { ser coletados e vendidos a } \\
\text { terceiros, para fins comerciais. }\end{array}$ & $\begin{array}{c}\text { Os dados fornecidos aos provedores de } \\
\text { aplicações não poderão ser repassados a } \\
\text { terceiros, o que mantém o princípio da } \\
\text { privacidade. Ao se desligar de um serviço, o } \\
\text { provedor de aplicações não poderá guardar } \\
\text { os dados do usuário. }\end{array}$ \\
\hline $\begin{array}{l}\text { Criação de conteúdos (sites, blogs, } \\
\text { wikis etc.) }\end{array}$ & $\begin{array}{c}\text { O provedor de aplicações podia } \\
\text { ser responsabilizado por conteúdo } \\
\text { publicado pelos usuários. }\end{array}$ & $\begin{array}{c}\text { O provedor de aplicações não poderá ser } \\
\text { responsabilizado por conteúdo publicado } \\
\text { por seus usuários e esse conteúdo só poderá } \\
\text { ser retirado do ar mediante ordem judicial. }\end{array}$ \\
\hline $\begin{array}{l}\text { Formas de comunicação na } \\
\text { internet: }\end{array}$ & $\begin{array}{c}\text { Os provedores de conexão } \\
\text { - em tempo real; } \\
\text { correio eletrônico; } \\
\text {-grupos e fóruns de discussão. }\end{array}$ & $\begin{array}{c}\text { A neutralidade de rede obriga os provedores } \\
\text { de conexão a tratarem de maneira igual toda } \\
\text { conforme o serviço utilizado sem } \\
\text { restrição alguma. } \\
\text { informão que trafega na rede; são proibidas } \\
\text { distinges em razão do tipo, origem ou }\end{array}$ \\
\hline
\end{tabular}

Fonte: adaptado da Lei 12.965/2014.

Como visto, o Marco Civil traz regulamentações que geram impactos no tocante às atividades realizadas pelos usuários na internet. Tais princípios, garantias, direitos e deveres estão sendo rediscutidos de maneira democrática a fim de especificar claramente o que será permitido ou não com o decreto de regulamentação da Lei 12.965. Os principais pontos que geram polêmicas e carecem de especificação detalhada de regulamentação são os que tratam da questão da neutralidade da rede e da privacidade dos dados pessoais e comunicações privadas. Será necessário detalhar no decreto as exceções da neutralidade da rede e as condições em que isso poderá ocorrer. Alguns casos que poderão ser priorizados a respeito do tráfego de dados já têm sido discutidos, por exemplo, segurança pública ou telemedicina. Quanto à manutenção da privacidade dos dados pessoais e comunicações privadas, existe preocupação sobre como poderá ser feita a identificação individualizada do usuário nos casos em que ele for responsabilizado por crimes na internet. O Marco Civil não especifica como os provedores de 
internet e de aplicações deverão fazer a guarda dos dados de usuários visto que, caso não sejam mantidos os dados técnicos necessários e de maneira adequada, será difícil identificar criminosos na internet.

\section{Considerações finais}

Este trabalho apresentou uma análise da recente lei que rege o uso da internet no Brasil. O Marco Civil da Internet pode ser considerado uma norma regulatória ampla e que aborda vários temas relevantes. Trata-se de uma lei considerada sofisticada e vanguardista que prevê princípios como a neutralidade e privacidade, além do multissetorialismo que garante que a internet seja governada por todos os setores, desde o governo até a sociedade civil.

Deve ser ressaltado o importante aspecto colaborativo na criação do Marco Civil. Tratou-se de um processo pioneiro no país, o qual teve a presença de cidadãos e entidades representativas, que contribuíram com a criação de uma lei, e o mais importante, uma lei que os beneficia diretamente. Talvez por isso o conteúdo abordado, mesmo sendo considerado sofisticado a respeito das diretrizes que compõem o texto, apresente por alguns estudiosos um caráter generalista e superficial se comparado a outros países. Pode-se considerar, entretanto, que o Brasil possui hoje uma das leis mais progressistas do mundo no que se refere ao uso da internet.

Há cerca de nove meses após a sua aprovação, uma consulta pública foi lançada com o objetivo de aprofundar e detalhar tópicos apresentados no Marco Civil, o que viabilizará e consolidará sua aplicabilidade por meio do decreto de regulamentação. Tal situação enriquece o teor dessa lei brasileira e traz a reabertura de debate sobre a neutralidade da rede prevista na lei. Os defensores afirmam que o item é importante para que provedores de internet não possam determinar que um conteúdo seja acessado com mais velocidade do que outro. As operadoras argumentam que a neutralidade impede a realização de promoções que prevejam diferentes velocidades. Um outro ponto polêmico é a questão da proteção aos registros, dados pessoais e comunicação privada. Deve-se especificar claramente como e quais dados dos usuários devem ser mantidos. 
Tais especificações e questões tratadas na lei do Marco Civil favorecem o surgimento de melhoria nos serviços de navegação uma vez que a inovação passa a ser um fator determinante nos modelos de negócios utilizados pelos provedores de acesso, conteúdo e aplicações. Esses agentes estão sendo obrigados a buscar novos arranjos e ofertas customizadas capazes de atrair e fidelizar usuários.

O cenário colaborativo conferido à criação do Marco Civil da Internet no Brasil trouxe à tona a necessidade de se criar, realizar revisões e atualizações de leis, dentre elas a Lei dos Direitos Autorais (Lei 9.610/1998) e a Lei de Proteção de Dados Pessoais que está em fase de anteprojeto de lei e é amplamente discutida com a sociedade. Essas duas regulamentações estão intimamente relacionada com as questões que permeiam o uso da internet.

\section{Referências}

Aragão, A. (2014). Dilma sanciona Marco Civil na abertura do NETMundial. Folha de S. Paulo. Recuperado em http://www1.folha.uol.com. $\mathrm{br} /$ tec/2014/04/1444200-dilma-sanciona-marco-civil-na-abertura-do-netmundial.shtml [Acesso em: 14 maio 2014].

Araújo, E. N. e Rocha, E. M. P. da (2009). Trajetória da sociedade da informação no Brasil: proposta de mensuração por meio de um indicador sintético. Ci. Inf., 38(3), 9-20. DOI: 10.1590/S010019652009000300001. Recuperado em http://www.scielo.br/scielo.php?script=sci_arttext\&pid=S0100-19652009000300001\&lng $=$ en $\& n r m=$ iso [Acesso em: 9 jun. 2014].

Araya, E. R. e Vidotti, S. A. B. G. (2010). Criação, proteção e uso legal de informação em ambientes da World Wide Web. São Paulo: Cultura Acadêmica.

Benakouche, T. (1997). Redes técnicas - redes sociais: a pré-história da Internet no Brasil. Revista USP, 35, 125-133. 
Bernes-Lee, T. (2014). Precisamos de uma Carta Magna para a Internet. Brasil Post. Recuperado em http://www.brasilpost.com. br/tim-bernerslee/precisamos-de-uma-magna-carta-para-ainternet_b_5311698.html [Acesso em: 16 maio 2014].

Bonatelli, C. (2010). Consulta expõe controvérsias do Marco Civil da Internet. O Estado de S. Paulo. Recuperado em <http://www.estadao. com.br/noticias/geral,consulta-expoe-controversias-do-marco-civil-da-internet,545285,0.htm > [Acesso em: 25 abril 2014].

Brasil (2011a). Presidente (2011-2014: Rousseff). Mensagem enviada ao Congresso Nacional em 24 de agosto de 2011[por] Dilma Rousseff, presidente da República do Brasil. Brasília: [s.n.], 2011 a.

Brasil (2011b).Lei no. 12.965, de 24 de abril de 2014. Diário da Câmara dos Deputados, LXVI( 225), 68.801. Estabelece princípios, garantias, direitos e deveres para o uso da Internet no Brasil. Recuperado em <http://www.planalto.gov.br/ccivil_03/_ato2011-2014/2014/ lei/112965.htm> [Acesso em: 11 nov. 2014].

Brasil (1995a). Portaria Interministerial no 147, de 31 de maio de 1995. Brasília, 1995. Recuperado em <http://www.cgi.br/portarias/numero/147> [Acesso em: 9 jun. 2014].

Brasil (1995b). Portaria Interministerial no 148, de 31 de maio de 1995. Aprova a Norma no 004/95 - Uso da Rede Pública de Telecomunicações para acesso à Internet. Brasília, 1995. Recuperado em <http://legislacao.anatel.gov.br/normas-do-mc/78-portaria-148> [Acesso em: 8 jun. 2014].

Carvalho, J. M. de, Arita, C.H. e Nunes, A. de F. (1999). A política de implantação da Internet no Brasil. Recuperado em http://www.portcom. intercom.org.br/pdfs/5be0d57f5fde664d948d9c2cbc80b619. PDF [Acesso em: 2 jun. 2014]. 
Carvalho, M. S. R. M. de. (2006). A trajetória da internet no Brasil: do surgimento das redes de computadores à instituição dos mecanismos de governança (Dissertação de Mestrado). Universidade Federal do Rio de Janeiro, Rio de Janeiro.

Centro de Estudos sobre as Tecnologias de Informação e Comunicação. (2014). TIC domicilios e empresas 2013: pesquisa sobre o uso das tecnologias da informação e comunicação no Brasil. São Paulo: Comitê Gestor da Internet no Brasil.

Comitê Gestor da Internet no Brasil (2009). Resolução CGI.br/RES/003. Princípios para a Governança e uso da Internet no Brasil (CGI.br) RES/2009/003/P). Recuperado em <http://www.cgi.br/resolucoes/documento/2009/003> [Acesso em: 10 nov. 2014].

Comitê Gestor da Internet no Brasil (2014). Resolução CGI.br/ RES/2014/009. Grupo de Trabalho sobre Governança da Internet. Recuperado em <http://www.cgi.br/resolucoes/documento/2014/009> [Acesso em: 10 nov. 2014].

Comscore (org.) (2013). Brazil digital future in focus 2013: key insights from 2012 and what they mean for the coming year. Recuperado em $<$ http://pt.slideshare.net/renatogalisteu/brazil-digital-future-infocus-2013-comscore-maro-2013> [Acesso em: 10 nov. 2014].

Embratel lança acesso comercial à Internet (1994). Folha de S. Paulo. Recuperado em http://www1.folha.uol.com.br/fsp/1994/12/21/dinheiro/8.html [Acesso em: 4 jun. 2014].

Fundação Getúlio Vargas (2009). Marco Regulatório Civil para a Internet Brasileira. Recuperado em http://direitorio.fgv.br/evento/marco-regulatorio-civil-para-a-internet-brasileira [Acesso em: 22 abril 2014].

Instituto Brasileiro de Geografia e Estatística (2005). Acesso à Internet e uso pessoal de telefone móvel celular para uso pessoal. Recuperado 
em <http://www.ibge.gov.br/home/estatistica/populacao/acessoainternet/>. [Acesso em: 10 nov. 2014].

Instituto Brasileiro de Geografia e Estatística (2011). Acesso à Internet e uso pessoal de telefone móvel celular para uso pessoal. Recuperado em <http://www.ibge.gov.br/home/estatistica/populacao/acessoainternet2011/> [Acesso em: 10 nov. 2014].

Lemos, R. (2010). Marco Civil é lei a favor da internet. Folha de S. Paulo. Recuperado em < http://www1.folha.uol.com.br/fsp/opiniao/ fz1205201008.htm $>$ [Acesso em: 12 maio 2014].

Lutfi, Adriana (1999). Usuário tem mais opções para acesso de alta velocidade à rede. Folha de S. Paulo. Recuperado em http://www1.folha.uol.com. br/fsp/informat/fr0112199919.htm [Acesso em: 10 jun. 2014].

Marco Civil. (2014). Marco civil da internet: seus direitos e deveres em discussão. Recuperado em http://culturadigital.br/marcocivil/ [Acesso em: 10 nov. 2014].

Marques, I. da C. (2000). Reserva de mercado: um mal entendido caso político-tecnológico de "sucesso" democrático e "fracasso" autoritário. Revista de Economia, 24, 89-114.

Menezes, E. T. de e Santos, T. H. dos. (2014). SocInfo (Programa Sociedade da Informação). Dicionário Interativo da Educação Brasileira. Recuperado em http://www.educabrasil.com.br/eb/dic/dicionario.asp?id=470 [Acesso em: 9 jun. 2014].

NetMundial (2014). NETMundial Multistakeholder Statement. Recuperado em http://netmundial.br/wp-content/uploads/2014/04/ NETmundial-Multistakeholder-Document.pdf [Acesso em: 10 nov. 2014].

Oliveira, C. E. E. de (2014). Aspectos Principais da Lei no 12.965, de 2014, o Marco Civil da Internet: subsídios à comunidade jurídica. Núcleo 
de Estudos e Pesquisas/CONLEG/ Senado, 2014 (Texto para Discussão no 148). Recuperado em http://www12.senado.gov. $\mathrm{br} /$ publicacoes/estudos-legislativos/tipos-de-estudos/textospara-discussao/td-148-aspectos-principais-da-lei-no-12.965-de2014-o-marco-civil-da-internet-subsidios-a-comunidade-juridica. Acesso em: 17 maio 2014.

Santarém, P. R. da S. (2010). O direito achado na rede: a emergência do acesso à internet como direito fundamental no Brasil (Dissertação de Mestrado). Universidade de Brasília, Brasília.

Souza, R. H. V. de e Solagna, F. (2012). Tomando a SOPA e derrubando a PIPA: propriedade intelectual e mobilização transnacional. Em: Encontro Internacional de Ciências Sociais. (Anais). Ed. Universitária, Pelotas.

Universidade Estadual de Maringá (2006). História dos computadores no Brasil. Museu do computador. Recuperado em http://www.din. uem.br/museu/hist_nobrasil.htm . [Acesso em: 20 abril 2014].

We Are Social (2014). Global Digital Statistics 2014: We Are Social's Snapshot of Key Digital Indicators. Singapura: We Are Social.

Working Group on Internet Governance (2005). Report of the Working Group on Internet Governance. Recuperado em <http://www.wgig. org/docs/WGIGREPORT.pdf $>$ [Acesso em: 10 nov. 2014]. 